\title{
A Process Review of the Indashyikirwa Couples Curriculum to Prevent Intimate Partner Violence and Support Healthy, Equitable Relationships in Rwanda
}

\author{
Erin Stern ${ }^{1, *}$ and Ritha Nyiratunga ${ }^{2}$ \\ 1 The London School of Hygiene and Tropical Medicine, Keppel Street, London WC1E 7HT, UK \\ 2 Rwanda Men's Resource Centre, PO Box 3286, Kigali, Rwanda; rutaritha@rwamrec.org \\ * Correspondence: Erin.Stern@1shtm.ac.uk or erin.a.stern@gmail.com; Tel.: +250-784337689
}

Academic Editors: Dawn Hutchinson and Lori Underwood

Received: 29 April 2017; Accepted: 8 June 2017; Published: 13 June 2017

\begin{abstract}
Indashyikirwa is a Rwandan intimate partner violence (IPV) prevention program being implemented by CARE International Rwanda, Rwanda Women's Network (RWN), and Rwanda Men's Resource Centre (RWAMREC). A central aspect of the programme is a 20-session curriculum for heterosexual couples designed to support healthy, non-violent relationships. This paper draws on qualitative interviews with 15 couples (before and after the curriculum) and 9 field staff to assess couples' impressions, comprehension of, and engagement with this innovative training. Thematic analysis was conducted to compare key findings from both data sources. Couples and staff offered positive assessments of the curriculum including the contextual relevance, the participatory approach, and a high level of dedication to the training was shown by the majority of couples. Many couples appreciated being trained together, and although some men dominated the first few sessions, participation gradually became more gender-balanced, and facilitators emphasized creating a safe environment for equal participation. Curriculum content that was initially resisted or difficult reportedly became easier through couples learning and trying new skills and experiencing relationship benefits first-hand, which emphasizes the value of the skills building component and take home exercises. Important insights for couples-based, educational approaches to IPV prevention are identified from this process review.
\end{abstract}

Keywords: intimate partner violence; gender transformative intervention; curriculum; couples approaches

\section{Background}

Intimate partner violence (IPV), which includes physical or sexual forms of violence, psychological, and economic abuse within intimate relationships (Buzawa and Buzawa 2013), is the most common form of violence against women, with 30\% of women globally experiencing it during their lifetime (Devries et al. 2013). Interventions responding to IPV have traditionally sought to establish support services for victims and improve the criminal and health sector responses (Abramsky et al. 2012), Yet, there has been a more recent emphasis on interventions that prevent IPV. A promising IPV prevention approach is participatory group education to support individuals to identify the risk factors and consequences of IPV, and gain self-efficacy to prevent and respond to IPV (Campbell et al. 2013). Drawing on Freire (1973) concept of 'critical consciousness,' individuals are encouraged to interrogate gendered and social norms that underlie IPV and inequitable relations and develop alternative norms promoting non-violence. Interventions that are 'gender transformative' for aiming to shift harmful gender norms have been found to reduce underlying attitudes of or levels of IPV (Heise 2011; Slegh et al. 2013; Fulu et al. 2014). A review conducted by the World Health Organization, and London 
School of Hygiene and Tropical Medicine (2010) suggested that the most successful curriculum programmes to prevent IPV address gender norms and inequitable power dynamics; equip participants with skills to make healthy choices and improve conflict resolution; and implement the intervention for a minimum of six months.

Yet, difficult social contexts have been found to hinder the ability of small group education beneficiaries to maintain greater awareness and changed attitudes if their broader environment is not addressed (Campbell and Cornish 2010; Gibbs et al. 2015). This is particularly the case for IPV prevention efforts with women, given that women living in marginal economic and social conditions are more vulnerable to IPV (Kim et al. 2007). Evidence suggests that women who are dependent on a husband or male partner for financial security have reduced capacity to leave an abusive relationship (Buzawa and Buzawa 2013; Kaukinen et al. 2013). There is increasing verification of the value to combine such curriculum approaches with women's economic empowerment activities (Verma et al. 2006; Slegh et al. 2013). For instance, an evaluation of Stepping Stones, a sexual and reproductive health communication and relationship skills training implemented with men and women in the rural Eastern Cape of South Africa, found men's perpetration of IPV reduced after 24 months; however, there was no sustained impact on women's experiences of violence (Jewkes et al. 2008). One explanation for this was women's high economic dependency on men (Jewkes et al. 2010). Stepping Stones was subsequently combined with the intervention Creating Futures, which aims to strengthen young women and men's livelihoods in informal settlements. An evaluation of this piloted progamme found women and men had more gender-equitable attitudes, men reduced controlling behaviours towards partners, women felt less controlled by their partners and experienced less sexual and/or physical IPV (Jewkes et al. 2014). Another prominent example is the IMAGE intervention in South Africa, an IPV and HIV prevention programme which combined gender training with microfinance activities, and revealed a 55\% reduction in reported rates of IPV after two years (Pronyk et al. 2006).

Most economic empowerment initiatives in the Global South focus on women, yet in many settings, household decision-making continues to be dominated by men (Edström et al. 2015). Men who perceive themselves as economically marginalized can be more prone to commit IPV as a way to achieve some form of respect (Slegh et al. 2013; Gibbs et al. 2014). In some settings, men may consider women's income-generating activities as a threat to their provider roles (Slegh et al. 2013), which can be a trigger for conflict or IPV. It is, thus, vital to engage men in gender transformative efforts in support of women's economic empowerment. For instance, Journeys of Transformation (JoT) established by Promundo, CARE International Rwanda and Rwanda Men's Resource Centre (RWAMREC) implemented a programme with men whose partners were active VSLA (village savings and loan association) members in order to foster their support of women's economic empowerment and improve household dynamics. The programme drew on CARE's (2012) assessment of the Rwanda VSLAs, which found that many men were controlling the function of the groups and money, and a significant proportion of women did not feel confident to make decisions about a loan without their husband's approval. Men participated in 16 participatory sessions in groups and as couples, and a case controlled evaluation found the training reduced household-level poverty, had a positive impact on partners' collaboration around household and care work activities, partner and family relations, and decision-making, although it was difficult to confirm reduced IPV (Slegh et al. 2013).

Curriculum and livelihood strengthening approaches are restricted by the fact that change is supported only among those directly involved in the intervention. This is a limitation given the increasing recognition of the need to address the interplay of personal, situational and socio-cultural factors influencing IPV (Heise 2011; Abramsky et al. 2012; Kyegombe et al. 2014). Community mobilization strategies to prevent IPV are critical as when significant masses of people change their beliefs and behaviors, social norms can change, which reinforces the behaviour changes of individuals and families. Moreover, without ongoing activism around IPV prevention, social norms that condone IPV or regulate it to the private domain, are likely to be maintained (Abramsky et al. 2012). SASA! is a community mobilization IPV and HIV prevention intervention designed by Raising Voices, piloted 
in Kampala, Uganda, and now implemented in a wide range of countries globally. SASA! supports community members and diverse stakeholders, including government and service providers to engage in activism to prevent violence against women and HIV by changing social norms to balance power between men and women. SASA! is critically rooted in individual behaviour change theory and phased incrementally according to Knowledge, Attitudes, Behaviours and Skills. It uniquely identifies positive alternatives to IPV, and recognizes the multiple ways that power imbalances play out beyond a typical focus on gender roles (Kyegombe et al. 2014). This diverges from IPV prevention educational approaches that provide content without strong links to behaviour change, negate the emphasis on behaviours and skills building for healthy relationships, or solely focus on how and why IPV is problematic. A rigorous evaluation indicated that SASA! generated significant shifts in gender norms related to IPV, and found a 52\% reduction in past-year experience of physical IPV among women (Abramsky et al. 2012; Kyegombe et al. 2014).

In summary, while curriculum approaches to prevent IPV are auspicious, there is emerging evidence of the value to ground these approaches in behaviour change theory, with an emphasis on skills building and constructive alternatives to IPV. In many settings, there is also a need to combine curriculum approaches with strategies to empower women economically, in ways that engage both men and women, and in combination with efforts to shift social norms and power imbalances through community mobilization or activism. Couples IPV prevention programming critically engages men and confronts household gender and power dynamics that may constrain women's economic empowerment, which may also contribute to addressing women's vulnerability to IPV. Such principles were considered for the development of the Indashyikirwa couples curriculum.

\section{Study Setting and Couples Curriculum}

Indashyikirwa, which means "agents for change" in Kinyarwanda, is a four year (2014-2018) IPV prevention programme, funded by DFID Rwanda and being implemented by CARE International Rwanda, Rwanda Women's Network (RWN) and RWAMREC across 14 sectors $^{1}$ in three Rwandan provinces. The programme focuses on preventing IPV, for being one of the most prevalent forms of violence against women in Rwanda. According to the 2014/2015 Demographic and Health Survey, an estimated $20.7 \%$ of women aged $15-49$ reported having experienced physical or sexual violence by any husband/partner in the past 12 months, and 40\% of ever married women reported ever experiencing emotional, physical, and/or sexual violence by their intimate partner. A key component of the Indashyikirwa programme, and the focus of this paper, is the couples curriculum. The curriculum used CARE's village savings and loans associations (VSLAs) as an entry point (whereby at least one partner of a couple had to be an active VSLA member) of an interactive curriculum implemented with 840 heterosexual couples who were married or had been living together for at least six months. It is important to note that the VSLAs engage individuals from poor socio-economic backgrounds, which represents the majority of couples recruited for the curriculum. The participatory curriculum was designed to help couples positively transform power imbalances in their lives and relationships, equip couples to critically identify and manage triggers of IPV and build skills for equitable, non-violent relationships. The curriculum drew on adaptations and lessons learned from JoT and SASA!, with the latter's emphasis on positive ('power to', 'power with', 'power within') and negative ('power over') types and uses of power, and the benefits of non-violence and gender equity. The curriculum was structured along knowledge, attitudes, skills and behaviours and moved incrementally from intensive self-reflection to eventual actions to be taken at a community level. With support from an international consultant with expertise in SASA! and curriculum design, and the impact evaluation

1 Sectors are the third level administrative subdivision in Rwanda. The Provinces of Rwanda are subdivided into 30 districts, and each district is in turn divided into sectors, totaling 416 sectors. 
team, the implementation partners adapted and developed the curriculum for the Rwandan context and participants.

The curriculum had 20 sessions, which included foundational concepts of power and gender; rights and realities; causes, consequences, and managing triggers of violence including alcohol use, jealousy and economic inequalities; gender roles in the household; foundations of healthy relationships; introduction to activism and providing empowering responses to survivors of gender based violence (GBV) in order to minimize their sense of shame or stigma. The training included take-home exercises for couples to consolidate and strengthen their learning, and offered skills building in key areas around triggers of IPV. Before implementation, the curriculum was pre-tested in one location from August-September 2015. One CARE Rwanda staff member and one to two external researchers, including the first author, observed each session. After each session, focus groups were conducted separately with male and female participants, facilitated by same-sex interviewers, and interviews were conducted with each RWAMREC facilitator, to assess their impressions and understanding of the sessions. Daily notes were compiled documenting insights around participant engagement, comprehension and quality of activities, which were compiled into weekly memos with key recommendations for refining the approach and content of the curriculum.

Across 28 sites, the curriculum was implemented with 15 couples, once a week, from November 2016 to May 2017. To cover transport costs and the time involved, each partner of a couple was paid RWF 2000 (approximately \$2.50 USD) per session. Each session lasted $3 \mathrm{~h}$ on average and was facilitated by a male and female RWAMREC facilitator. The value of having two facilitators of both genders was a critical lesson identified from pre-testing the curriculum. Prior to implementation and pre-testing of the curriculum, RWAMREC staff completed a two-week intensive training on the curriculum content and approach, including participatory methodologies and ensuring safe spaces for equal participation. At this training, staff practiced implementing curriculum sessions and modified them before the pre-test with community members. Each staff member had the opportunity to practice facilitating at least one session during the curriculum pre-test. All of the facilitators also had at least a few years of previous facilitation experience.

The couples curriculum is situated within the wider Indashyikirwa programme, which works to support an 'enabling environment' for change. Approximately $25 \%$ of individuals who completed the curriculum were further trained and are mentored by RWAMREC staff to engage community members on what they had learned using creative materials and outreach activities for an additional 22 months. In November 2015, RWN trained approximately 40 opinion leaders (e.g., local leaders, religious leaders, service providers, legal professionals) per intervention sector to encourage self-reflection on gender and power and promote more effective action on IPV prevention and response. Over the course of the intervention, RWN staff members meet with trained opinion leaders on a quarterly basis where they discuss their progress on actions committed to for IPV prevention and response, and plan ongoing efforts. In each intervention sector, RWN has implemented women's safe spaces, which are staffed by facilitators, drawn from women living in the intervention communities, who were trained to provide safe spaces for women to discuss experiences of IPV and gender inequality, educate women about their rights, and refer or accompany women who wish to report abuse or seek health or social services. These facilitators are also supported to engage in wider level advocacy on women's rights and IPV prevention.

\section{Research Objective}

This paper presents data from two rounds of interviews conducted with the same sub-set of couples in November 2015 (before enrolling in the couples curriculum), and in May 2016 (directly after completing the couples curriculum), as well as with RWAMREC staff in May 2016 to assess the process of this innovative couples curriculum. Key areas presented are couples' impressions of the training, comprehension, and engagement of couples, and facilitators' experiences of implementation. In May 2017, the same subset of couples were interviewed to assess longer-term impacts of the 
curriculum, and there is an ongoing RCT to assess the programme impact among couples. Valuable insights for the field of curriculum approaches to IPV prevention are nonetheless identified from this process review of the Indashyikirwa couples curriculum.

\section{Methods}

Interviews were conducted with couples in 3 of the 15 intervention sectors (Rurembo Sector, Western Province; Gacaca Sector, Northern Province; Gishari Sector, Eastern Province), which were purposefully selected to represent a diversity of environments including rural, urban and peri-urban locations. Thirty couples (10 in each of the three sectors) were interviewed after enrolling, but before starting the curriculum. A female and male Rwandan qualitative researcher external to the programme conducted interviews with female and male partners of couples separately. Interviews assessed their expectations of the curriculum, expectations of their partners, difficulties in their relationships, communication, and conflict resolution strategies. If either member of the couple mentioned violence, they were asked what started that episode of violence, how frequently it tends to happen, whether they have ever sought support, and if so from who including friends, family, health, or legal services. Twenty-eight couples (due to one couple being lost to follow up) were interviewed after completion of the curriculum to understand their immediate reflections and the influence of the training on them personally and in their relationships. For each interview, participants were given RWF 2000 as a token of appreciation. All interviews were conducted in Kinyarwanda, audio-recorded, and took place in preferred, private locations for interviewees. To triangulate the couples' perspectives, interviews were conducted with six RWAMREC field officers and three RWAMREC field supervisors across all intervention sectors to assess the successes and challenges of the curriculum. Participants' engagement with the sessions and facilitators' management of the groups was also assessed. These interviews were conducted in English by the first author and detailed notes were taken to capture responses.

Ethical approval to undertake the study was obtained from the Rwandan National Ethics Committee (RNEC) (REF:340/RNEC/2015), the National Institute of Statistics Rwanda (REF: 0738/2015/10/NISR), the South Africa Medical Research Council and the London School of Hygiene. Before each interview, written informed consent was obtained from participants in adherence with the ethical approval guidelines given by the respective review boards. Information on the aims, risks, and benefits of the research was provided to all participants during the informed consent process. All interviewees were made aware of their guaranteed confidentiality, no identifying information has been used, and quotes from couples are coded (see Table 1 for code descriptions and demographic information of couples). Among couples, the researchers emphasized that nothing would be shared with their partners.

Table 1. Demographics of couples interviewed.

\begin{tabular}{|c|c|c|c|c|c|c|}
\hline ID & Role & Gender & $\begin{array}{c}\text { Age (at Time of } \\
\text { Midline Interview) }\end{array}$ & Province & Marital Status & $\begin{array}{c}\text { Relationship } \\
\text { Duration (years) }\end{array}$ \\
\hline FC01W & Partner of Couple & Female & 29 & $\begin{array}{l}\text { Western } \\
\text { Province }\end{array}$ & $\begin{array}{l}\text { Informally } \\
\text { Married }\end{array}$ & 10 \\
\hline MC01W & Partner of Couple & Male & 38 & $\begin{array}{l}\text { Northern } \\
\text { Province }\end{array}$ & $\begin{array}{l}\text { Informally } \\
\text { Married }\end{array}$ & 10 \\
\hline FC02W & Partner of Couple & Female & 29 & $\begin{array}{l}\text { Western } \\
\text { Province }\end{array}$ & $\begin{array}{l}\text { Formally } \\
\text { Married }\end{array}$ & 8 \\
\hline $\mathrm{MC} 02 \mathrm{~W}$ & Partner of Couple & Male & 30 & $\begin{array}{l}\text { Western } \\
\text { Province }\end{array}$ & $\begin{array}{l}\text { Formally } \\
\text { Married }\end{array}$ & 8 \\
\hline FC03W & Partner of Couple & Female & 37 & $\begin{array}{l}\text { Western } \\
\text { Province }\end{array}$ & $\begin{array}{l}\text { Formally } \\
\text { Married }\end{array}$ & 17 \\
\hline MC03W & Partner of Couple & Male & 37 & $\begin{array}{l}\text { Western } \\
\text { Province }\end{array}$ & $\begin{array}{l}\text { Formally } \\
\text { Married }\end{array}$ & 17 \\
\hline FC04W & Partner of Couple & Female & 33 & $\begin{array}{l}\text { Western } \\
\text { Province }\end{array}$ & $\begin{array}{l}\text { Informally } \\
\text { Married }\end{array}$ & 14 \\
\hline
\end{tabular}


Table 1. Cont.

\begin{tabular}{|c|c|c|c|c|c|c|}
\hline ID & Role & Gender & $\begin{array}{c}\text { Age (at Time of } \\
\text { Midline Interview) }\end{array}$ & Province & Marital Status & $\begin{array}{c}\text { Relationship } \\
\text { Duration (years) }\end{array}$ \\
\hline MC04W & Partner of Couple & Male & 32 & $\begin{array}{l}\text { Western } \\
\text { Province }\end{array}$ & $\begin{array}{l}\text { Informally } \\
\text { Married }\end{array}$ & 14 \\
\hline FC05W & Partner of Couple & Female & 35 & $\begin{array}{l}\text { Western } \\
\text { Province }\end{array}$ & $\begin{array}{l}\text { Formally } \\
\text { Married }\end{array}$ & 15 \\
\hline MC05W & Partner of Couple & Male & 33 & $\begin{array}{l}\text { Western } \\
\text { Province }\end{array}$ & $\begin{array}{l}\text { Formally } \\
\text { Married }\end{array}$ & 15 \\
\hline FC01N & Partner of Couple & Female & 27 & $\begin{array}{l}\text { Northern } \\
\text { Province }\end{array}$ & $\begin{array}{l}\text { Formally } \\
\text { Married }\end{array}$ & 8 \\
\hline $\mathrm{MC} 01 \mathrm{~N}$ & Partner of Couple & Male & 36 & $\begin{array}{l}\text { Northern } \\
\text { Province }\end{array}$ & $\begin{array}{l}\text { Formally } \\
\text { Married }\end{array}$ & 8 \\
\hline $\mathrm{FC} 02 \mathrm{~N}$ & Partner of Couple & Female & 21 & $\begin{array}{l}\text { Northern } \\
\text { Province }\end{array}$ & $\begin{array}{l}\text { Informally } \\
\text { Married }\end{array}$ & 2 \\
\hline $\mathrm{MC} 02 \mathrm{~N}$ & Partner of Couple & Male & 23 & $\begin{array}{l}\text { Northern } \\
\text { Province }\end{array}$ & $\begin{array}{l}\text { Informally } \\
\text { Married }\end{array}$ & 2 \\
\hline FC03N & Partner of Couple & Female & 28 & $\begin{array}{l}\text { Northern } \\
\text { Province }\end{array}$ & $\begin{array}{l}\text { Informally } \\
\text { Married }\end{array}$ & 5 \\
\hline $\mathrm{MC} 03 \mathrm{~N}$ & Partner of Couple & Male & 30 & $\begin{array}{l}\text { Northern } \\
\text { Province }\end{array}$ & $\begin{array}{l}\text { Informally } \\
\text { married }\end{array}$ & 5 \\
\hline FC04N & Partner of Couple & Female & 27 & $\begin{array}{l}\text { Northern } \\
\text { Province }\end{array}$ & $\begin{array}{l}\text { Formally } \\
\text { Married }\end{array}$ & 9 \\
\hline $\mathrm{MC} 04 \mathrm{~N}$ & Partner of Couple & Male & 29 & $\begin{array}{l}\text { Northern } \\
\text { Province }\end{array}$ & $\begin{array}{l}\text { Formally } \\
\text { Married }\end{array}$ & 9 \\
\hline FC05N & Partner of Couple & Female & 45 & $\begin{array}{l}\text { Northern } \\
\text { Province }\end{array}$ & $\begin{array}{l}\text { Formally } \\
\text { Married }\end{array}$ & 22 \\
\hline $\mathrm{MC} 05 \mathrm{~N}$ & Partner of Couple & Male & 45 & $\begin{array}{l}\text { Northern } \\
\text { Province }\end{array}$ & $\begin{array}{l}\text { Formally } \\
\text { Married }\end{array}$ & 22 \\
\hline FC01E & Partner of Couple & Female & 45 & $\begin{array}{l}\text { Eastern } \\
\text { Province }\end{array}$ & $\begin{array}{l}\text { Informally } \\
\text { Married }\end{array}$ & 10 \\
\hline MC01E & Partner of Couple & Male & 42 & $\begin{array}{l}\text { Eastern } \\
\text { Province }\end{array}$ & $\begin{array}{l}\text { Informally } \\
\text { Married }\end{array}$ & 10 \\
\hline $\mathrm{FC} 02 \mathrm{E}$ & Partner of Couple & Female & 27 & $\begin{array}{l}\text { Eastern } \\
\text { Province }\end{array}$ & $\begin{array}{l}\text { Informally } \\
\text { Married }\end{array}$ & 5 \\
\hline MC02E & Partner of Couple & Male & 29 & $\begin{array}{l}\text { Eastern } \\
\text { Province }\end{array}$ & $\begin{array}{l}\text { Informally } \\
\text { Married }\end{array}$ & 5 \\
\hline FC03E & Partner of Couple & Female & 24 & $\begin{array}{l}\text { Eastern } \\
\text { Province }\end{array}$ & $\begin{array}{l}\text { Formally } \\
\text { Married }\end{array}$ & 4 \\
\hline MC03E & Partner of Couple & Male & 37 & $\begin{array}{l}\text { Eastern } \\
\text { Province }\end{array}$ & $\begin{array}{l}\text { Formally } \\
\text { Married }\end{array}$ & 4 \\
\hline FC04E & Partner of Couple & Female & 30 & $\begin{array}{l}\text { Eastern } \\
\text { Province }\end{array}$ & $\begin{array}{l}\text { Formally } \\
\text { Married }\end{array}$ & 10 \\
\hline MC04E & Partner of Couple & Male & 32 & $\begin{array}{l}\text { Eastern } \\
\text { Province }\end{array}$ & $\begin{array}{l}\text { Formally } \\
\text { Married }\end{array}$ & 10 \\
\hline FC05E & Partner of Couple & Female & 36 & $\begin{array}{l}\text { Eastern } \\
\text { Province }\end{array}$ & $\begin{array}{l}\text { Informally } \\
\text { Married }\end{array}$ & 3 \\
\hline MC05E & Partner of Couple & Male & 38 & $\begin{array}{l}\text { Eastern } \\
\text { Province }\end{array}$ & $\begin{array}{l}\text { Informally } \\
\text { Married }\end{array}$ & 3 \\
\hline
\end{tabular}

During field collection with couples, the first author and qualitative researchers debriefed on a daily basis to record notes on impressions, contextual details, and non-verbal expressions, which were used for the analysis. The interviews conducted in Kinyarwanda were translated and transcribed verbatim directly into English. After carefully reading the transcripts from staff and couples, a preliminary coding structure was established by the first author to analyse the data systematically. Data were then further coded using principles of thematic analysis with the assistance of NVIVO 10 software (QSR International 2010, Melbourne, Australia). An additional transcriber also coded a small sub-set of the transcripts from the interviews with couples using NVIVO 10 and inter-coder agreement was found to be $95 \%$. The first author regularly workshopped the emerging findings with senior Indashyikirwa 
programme staff, including the second author, who played a critical role in verifying the analysis and interpretation of the data.

\section{Findings}

Impressions of the Couples Curriculum

\section{Appreciation of Curriculum Content and Approach}

Overall, couples and staff positively evaluated the curriculum. Couples especially appreciated the participatory approach, relevance of the content, and the skilled facilitators. There was extremely high retention and regular attendance at the sessions, indicative of couples' ongoing commitment and interest, as expressed by one male partner of a couple: "I agreed with everything and I even wished there are more lessons. I didn't absent myself even once, even when I was ill I could come." $\left(\mathrm{MC} 5 \mathrm{EM}^{2}\right)$ The positive and inspiring approach, with the intention to improve relationships, was highly appreciated by couples. A field supervisor reflected on how the sequential design of the curriculum and relevant topics supported such active participation:

"The way these sessions were aligned for starting the journey; the concept of power, triggers of violence, overcoming excessive alcohol, gender, sexuality, all these concepts were logically answering their questions to the extent that no one could dare to miss a session because every day was a hit."

A few staff members and several partners of couples commended being trained as couples. One field officer noted how this supported their active participation: "they really liked how they were trained as couples, being with their partner, and taking time to be together. This helped them to be encouraged, to participate in the training." One male partner of a couple remarked how rare it was to be trained as couples: "this training helped us so much because this was my first time to see a married couple attend a training, being together, a training that talks to both of them." (MC02WM) Many couples found it helpful to identify common triggers and consequences of IPV and to learn skills to manage such triggers. Indeed, the skills-building component of the curriculum to strengthen relationships was highly appreciated. For instance, couples reported the value of learning and practicing conflict resolution skills, constructive criticism, open communication, and asking for forgiveness for previous conflicts. A few couples and staff also shared couples' appreciation of learning community IPV prevention and response skills including how to actively listen and provide non-judgmental responses to those experiencing IPV, and more safely intervene in conflict or violence.

Staff members and couples concurred that both men and women strongly related to the foundational concept of positive and negative types of power, and the linkages between 'power over' and the various types of IPV (economic, emotional, physical, sexual): "the lesson that I see that has been the most useful and that he talks about often is the lesson about power. The problem of power was about to destroy our marriage as he thought he was holding all the power." (FC01NM) Some female partners of couples and a few staff members discussed how women's self-confidence improved though learning about their power within:

"Now I openly speak out and I use the power that I have in me and I feel there is something that I can do to make my family developed. That is a very big thing". (FC04EM)

A few staff members and female partners of couples expressed women's appreciation for the session on gender roles in the home for indicating the responsibilities women typically bear and for valuing such work. A few staff members and several partners of couples reported that the session on rights and laws was particularly engaging and accessible: "rights and realities was relevant because 
it dealt with land and IPV laws which concerns everyone in these areas and were not complex or abstract issues related to laws." (Field Supervisor). Women in particular appreciated learning about their rights, including to property and to live free of IPV. Several couples appreciated learning the value of and practicing communication and joint decision-making around finances. This could lead to greater household development, and for some couples, greater use of and improved access to the VSLAs, highlighting the links with the micro-finance component of the curriculum:

"I used to feel I had to be the one to say how to spend money and that my wife didn't have a say because she had not worked for that money. But after having seen that when I go to work my wife does other housework, we put together what we have both done, we put the money at the bank or at the VSLAs since we are members of the group. We learned to save and how to spend the rest of the money. That has helped us." (MC01WM)

Initial Disagreement with Curriculum Content

Curriculum components that some couples did not initially appreciate or disagreed with were identified. A few staff members and several partners of couples noted how some men and women were initially reluctant to men sharing household and domestic duties due to concerns that men cannot perform tasks assigned for women, that this reflects badly on women, and/or husbands could be stigmatized for performing such duties. Yet, staff and couples spoke of testimonies of gradual changes in this domain. One field officer asserted how through trying new activities, and experiencing the household benefits, some couples' attitudes and practices shifted, indicative of the value of the skills building curriculum component:

“They are just reluctant because they have never tried it; it is something really new. But when they tried it they liked it. The women realized they cannot do this all on their own. The men realized it is good for the family for them to help."

Many field officers and several male partners of couples discussed the struggle for men to reduce their alcohol use, related to the social expectations for men to drink regularly, but noted that this became easier upon realizing the costs of harmful drinking, and the financial and relationship benefits of minimizing this:

"After drinking I felt, I am a man and I would commit violence against my wife but after having studied about alcohol, I realized it prevents me from reaching any household development. Now I am no longer a drunkard. I am now a person who builds his family and my family has noticed that I have changed. We became Indashyikirwa." (MC04NM)

A few male partners of couples reported initially disagreeing about sharing resource and property decisions with their wives, but becoming more supportive upon realizing the economic benefits and women's rights to such decision-making under the law. A few male partners of couples and field officers reported men's initial struggle to consider their power over women as problematic, or thought the sessions were teaching women to have power over men. However, this could shift through identifying the benefits of balancing power, and that both men and women can use power positively and negatively. As one field officer noted:

"Men were asking negatively 'what is this? They want women to be above us. But after every single session, you see men start to be open and realize how they were using power over, they thought it was their right as men to give directions to their families, go out and drink, do whatever they want, and come home late."

A few staff members, male and female partners of couples noted their initial resistance to the notion that women can initiate sex or that men do not have the right to always have sex with their wives. Yet, some attitude shift was reported after reflecting on the benefits of consensual sex and open 
communication about sex, learning about the legal rights to consensual sex, and the consequences of non-consensual sex:

"I felt sex was my responsibility alone and that whenever I needed to have sexual intercourse I had that right. Our culture and society tells us that a wife has to wait for what you give her; you are the one to decide what she needs. But after starting these trainings, I discovered many things that we have been ignoring because of our culture that we copied from our ancestors. I learnt that my wife also has a right to initiate sexual intercourse, which was something new for me." (MC03EM)

A field officer noted the importance of encouraging participatory discussions when participants disagreed with certain content: "we use participatory methods. If we respond I can confuse them and they say 'it is because you are a facilitator.' If one asks a question, I ask another who can respond."

\section{Curriculum Comprehension}

\section{Curriculum Comprehension Successes}

Overall, the curriculum was said to be highly comprehensive amongst the participants. One field officer asserted how the pre-test of the curriculum improved the translations from English into Kinyarwanda, which supported couples' understanding. The methods used within the curriculum, which were carefully designed for use in the Rwandan context were also said to aid comprehension, which was appropriate for the relatively low educational backgrounds of most participants: "we had some couples who could not read or write but the way the sessions are delivered and the steps of each session and how they follow each other with part one and part two is helpful for understanding." (Field Supervisor). One female partner of a couple reflected how completing the training with her husband supported their joint understanding as a couple:

"When there is a lesson that one of us didn't understand, we explain it to each other. We have the same perception because we both followed all the lessons." (FC04NM)

Both staff and couples concurred that the take home exercises equipped couples' understanding:

"When we came for the next lesson, we first answered the questions we were given in the homework so even the one who had not understood had an opportunity to understand.

So there is no lesson I didn't understand." (FC05EM)

\section{Curriculum Comprehension Challenges}

Many staff members noted that at the beginning of the curriculum some participants, especially men, were not completing the take home exercises because of having limited time together as couples, or not feeling comfortable with the exercises if they involved reading or writing. Staff members discussed how the completion of take-home exercises improved through asking participants to give feedback and reflect on the benefits of the exercises at the beginning of each session, informing them they did not have to write down these exercises, and asking those who were not completing the exercises to indicate why. Curriculum concepts that some couples and staff members identified as difficult to initially understand and/or enact included the distinction of gender and sex, concepts of activism and ways to provide empowering responses to GBV survivors such as being validating, inclusive, and giving options instead of advice, and details and sentences of the laws introduced. Yet, the majority of couples and staff conceded that the participatory approach, for encouraging critical thinking, personal testimonies, and ongoing discussion and debate, improved their understanding over the duration of the curriculum.

\section{Co-Facilitation and Counselling}

All of the staff expressed the significant value of co-facilitation to better support illiterate couples, give each other feedback on their facilitation skills, allow one facilitator to privately respond to 
participants' emotional distress, and to ensure completion of the sessions. A few field officers discussed how many participants appreciated having a male and female facilitator, which was helpful for encouraging equal participation from men and women, separating men and women for some activities, and since couples often preferred to seek counselling from facilitators of the same sex. Indeed, the majority of field officers reported being asked to offer individual and couples counselling, which was attributed to the sensitive content, and the close relationships they built with couples. As one field supervisor reflected: "When I did field visits with the field officers I found they knew each couple; their problems, their weaknesses, their strengths. It was very positive to see that." Some field officers discussed offering couples referrals for further counselling to the Indashyikirwa women's safe spaces, which were established to offer support to individuals experiencing IPV, refer and accompany individuals to health, legal, and social services, as needed. Two field supervisors asserted that field officers require more support in this domain given the extent of counselling requested by couples, and one field supervisor suggested having a professional counsellor available: "Some couples were referred to women's space, they accept this referral, but we do not have a follow up. It may be difficult for them to go. They need more support."

\section{Engagement of Couples}

There was general consensus by staff and couples of the safe spaces created at the curriculum sessions, and how couples were generally open about personal experiences. One female partner of a couple remarked that such openness helped couples better understand each other:

"Because we were in a secure and discrete place, everyone was free to say what he/she thinks. Because everyone freely said what was on his/her mind, everyone went back at his/her home knowing what his/her partner likes and dislikes." (FC01WM)

A field supervisor and a few partners of couples reflected how couples in each group developed close relationships and some supported each other with relationship difficulties. Several field officers related how male partners of couples tended to dominate the first few curriculum sessions, and women were more intimidated to speak in front of their partners, yet this became more balanced over time through emphasizing balancing power, safe spaces, and encouraging women's active participation. A few staff members noted that separating men and women for some activities was helpful for encouraging women's active participation, particularly for more taboo topics such as sexuality. However, one field officer noted that couples in her group requested to stay together and that "we did not separate after that. The women would talk about everything in front of their husbands." A few field officers reflected on the challenge for women with young babies to wholly participate in the sessions. A few staff members indicated that older participants could be more resistant to content around changing gender roles and norms: "The old men said 'how can I prepare a bed, even the woman can think I am mad?!' Please engage the young ones. For us we can't now change." (Field Supervisor). Despite these identified challenges, staff generally concurred that participatory techniques, including inviting those who are quiet to contribute to the group discussions, and emphasizing that there are no right or wrong answers, helped ensure active participation from all participants.

\section{Limitations}

As the data is based on the perceptions of couples and staff immediately after completing the curriculum, the responses may be limited by social biases. This may especially be the case among couples for being reluctant to critique a programme they benefited from. It was however emphasized that the researchers were external to the programme, and the same researchers conducted the baseline and midline interviews with couples, which was helpful for building rapport. 


\section{Discussion}

The findings speak to the value of interviewing both partners of couples, which is relatively uncommon in IPV prevention research, although there have been recent calls for this (Davis et al. 2012; Wadsworth and Markman 2012; Starmann et al. 2017). The findings further identify the importance of interviewing curriculum implementers, perspectives that are often neglected by impact evaluations. The interviews with staff generated insights into the 'how to' of the curriculum, including how to engage participants meaningfully, enhance their comprehension, encourage completion of the take-home exercises, and the value of co-facilitation. They also highlighted the need to equip facilitators with basic counselling awareness, understandings of vicarious trauma, and provided opportunities for regular debriefs.

This process review illustrates the importance of allowing time and external support for adaptation of such curricula. Indashyikirwa had a one-year inception phase to develop and pre-test the curriculum, as well as the underlying theory of change and broader programme design. This inception period allowed time to draw on core characteristics responsible for effective programmes (JoT, SASA!), and develop the curriculum to be appropriate for the participants, considering their developmental level, cultural norms, language, literacy, etc. These preliminary findings solidify the appropriateness, relevance, and accessibility of the curriculum topics. Pre-testing the curriculum supported this process, generated important insights relevant to successful implementation, and additionally developed staff's capacity to use a participatory approach, and ensure safe spaces to equally engage participants. The strong comprehension and dedication of couples was highly attributed to the participatory approach and quality facilitation skills of the staff.

Couples especially appreciated the rarity of being trained together, and having the opportunity to better understand and implement what they learned in their relationships. Other studies have found engaging couples can be more effective than separating men and women to equip change in relationships and reduce IPV (El-Bassel and Wechsberg 2012; Starmann et al. 2017). Mixed-group educational efforts can model equitable gender relations, mobilise men's care for the women and girls in their lives, and enhance their accountability to women (Anderson and Whiston 2005). A further emerging insight from the data is couples' appreciation of a positive, inspiring approach to build healthy, equitable relationships. The skills building component and use of take home exercises helped couples apply and often benefit from learnings and mitigate resistance to certain topics. This finding reinforces an assessment among a sub-set of couples exposed to SASA! in Uganda, which suggested the value of leaning relationship skills for conflict and IPV prevention (Starmann et al. 2017). The concept of positive and negative types and uses of power appears to be fundamental to the process of change for couples to identify causes and consequences of various forms of IPV, and support their ability to prevent and respond to IPV in their own relationships and within their communities. Overall, this preliminarily review of the curriculum speaks to the value of couples, educational approaches that emphasize the benefits of positive alternatives to IPV, equip couples with skills for building healthy, non-violent relationships, and are rooted in a broad understanding of a multitude of power imbalances.

Acknowledgments: The trial is being conducted as part of the portfolio of research of the What Works to Prevent Violence? A Global Programme on Violence against Women and Girls (VAWG) funded by the UK Government's Department for International Development (DFID). The Global Programme funded research into 16 interventions in 14 countries to assess the effectiveness of the interventions in prevention of VAWG. The work is being conducted in Africa, the Middle East, and Asia, between 2014 and 2018. We would like to acknowledge the co-investigators of the impact evaluation of Indashyikirwa; Lori Heise, Lyndsay McLean, and Kristin Dunkle. We also wish to acknowledge the input and support from the implementing partners: CARE International Rwanda, RWARMEC, and RWN, as well as the participants who were willing to share their experiences. Thanks to Robyn Yaker, who supported the design of the couples curriculum, conducted the training of the RWAMREC facilitators, and provided inputs to this paper.

Author Contributions: Erin Stern co-designed the study with the other investigators of the Indashyikirwa trial, conducted the interviews with staff, analyzed the data and wrote the paper. Ritha Nyiratunga provided input at analysis workshops hosted by Erin Stern, provided feedback to the paper and verified programmatic and contextual details. 
Conflicts of Interest: The authors declare no conflict of interest.

\section{References}

Abramsky, Tanya, Karen Devries, Ligia Kiss, Leilani Francisco, Janet Nakuti, Tina Musuya, Nambusi Kyegombe, Elizabeth Starmann, Dan Kaye, Lori Michau, and et al. 2012. A community mobilisation intervention to prevent violence against women and reduce HIV/AIDS risk in Kampala, Uganda (the SASA! Study): Study protocol for a cluster randomised controlled trial. Trials 13: 96. [CrossRef] [PubMed]

Anderson, Linda A., and Susan C. Whiston. 2005. Sexual Assault Education Programs: A Meta-Analytic Examination of Their Effectiveness. Psychology of Women Quarterly 29: 374-88. [CrossRef]

Buzawa, Eve S., and Carl G. Buzawa. 2013. What Does Research Suggest Are the Primary Risk and Protective Factors for Intimate Partner Violence (IPV) and What Is the Role of Economic Factors? Journal of Policy Analysis and Management 32: 128-37. [CrossRef]

Campbell, Catherine, and Flora Cornish. 2010. Towards a "fourth generation" of approaches to HIV/AIDS management: creating contexts for effective community mobilisation. AIDS Care 22: 1569-79. [CrossRef] [PubMed]

Campbell, Catherine, Kerry Scott, Mercy Nhamo, Constance Nyamukapa, Claudius Madanhire, Morten Skovdal, Lorraine Sherr, and Simon Gregson. 2013. Social capital and HIV Competent Communities: The role of community groups in managing HIV/AIDS in rural Zimbabwe. AIDS Care 25: S114-22. [CrossRef] [PubMed]

Davis, Sean D., Jay L. Lebow, and Douglas H. Sprenkle. 2012. Common factors of change in couple therapy. Behavior Therapy 43: 36-48. [CrossRef] [PubMed]

Devries, Karen M., Joelle. Y. Mak, Claudia Garcia-Moreno, Max Petzold, Jennifer C. Child, Gail Falder, Stephen Lim, Loraine J. Bacchus, Rebecca E. Engell, Lisa Rosenfeld, and et al. 2013. Global health. The global prevalence of intimate partner violence against women. Science 340: 1527-28. [CrossRef] [PubMed]

Edström, Jerker, Alexa Hassink, Thea Shahrokh, and Erin Stern. 2015. Engendering Men: A Collaborative Review of Evidence on Men and Boys in Social Change and Gender Equality. In EMERGE Evidence Review Promundo-US, Sonke Gender Justice. Brighton: Institute of Development Studies.

El-Bassel, Nabila, and Wendee M. Wechsberg. 2012. Couple-based behavioral HIV interventions: Placing HIV risk-reduction responsibility and agency on the female and male dyad. Couple and Family Psychology: Research and Practice 1: 94-105. [CrossRef]

Freire, Paolo. 1973. Education as the Practice of Freedom. In Education for Critical Consciousness. New York: Continuum.

Fulu, Emma, Alice Kerr-Wilson, and James Lang. 2014. What Works to Prevent Violence against Women and Girls? Evidence Review of Interventions to Prevent Violence against Women and Girls; London: UK Department for International Development.

Gibbs, Andrew, Rachel Jewkes, Yandisa Sikweyiya, and Samantha Willan. 2015. Reconstructing masculinity? A qualitative evaluation of the Stepping Stones and Creating Futures interventions in urban informal settlements in South Africa. Culture, Health \& Sexuality 17: 208-22. [CrossRef]

Gibbs, Andrew, Yandisa Sikweyiya, and Rachel Jewkes. 2014. 'Men value their dignity': Securing respect and identity construction in urban informal settlements in South Africa. Global Health Action 7: 23676. [CrossRef] [PubMed]

Heise, L. 2011. What works to prevent partner violence? An evidence overview . Working paper. Policy Division of the UK Department for International Development (DFID), London, UK. Available online: https:/ / www.oecd.org/derec/49872444.pdf (accessed on 9 June 2017).

Jewkes, Rachel, Andrew Gibbs, Nwabisa Jama-Shai, Samantha Willan, Alison Misselhorn, Mildred Mushinga, Laura Washington, Nompumelelo Mbatha, and Yandisa Skiweyiya. 2014. Stepping Stones and Creating Futures intervention: Shortened interrupted time series evaluation of a behavioural and structural health promotion and violence prevention intervention for young people in informal settlements in Durban, South Africa. BMC Public Health 14: 1325. [CrossRef] [PubMed]

Jewkes, Rachel, Mzikazi Nduna, Jonathan Levin, Nwabisa Jama, Kristin Dunkle, Adrian Puren, and Nata Duvvury. 2008. Impact of stepping stones on incidence of HIV and HSV-2 and sexual behaviour in rural South Africa: Cluster randomised controlled trial. BMJ 337: a506. [CrossRef] [PubMed] 
Jewkes, Rachel, Katharine Wood, and Nata Duvvury. 2010. 'I woke up after I joined Stepping Stones': Meanings of an HIV behavioural intervention in rural South African young people's lives. Health Education Research 25: 1074-84. [CrossRef] [PubMed]

Kaukinen, Catherine Elizabeth, Silke Meyer, and Caroline Akers. 2013. Status compatibility and help-seeking behaviors among female intimate partner violence victims. Journal Interpersonal Violence 28: 577-601. [CrossRef] [PubMed]

Kim, Julia C., Charlotte H. Watts, James R. Hargreaves, Luceth X. Ndhlovu, Godfrey Phetla, Linda A. Morison, Joanna Busza, John D.H. Porter, and Paul Pronyk. 2007. Understanding the Impact of a Microfinance-Based Intervention on Women's Empowerment and the Reduction of Intimate Partner Violence in South Africa. American Journal of Public Health 97: 1794-802. [CrossRef] [PubMed]

Kyegombe, Nambusi, Nambusi Starmann, Karen M. Devries, Lori Michau, Janet Nakuti, Tina Musuya, Charlotte Watts, and Lori Heise. 2014. 'SASA! is the medicine that treats violence'. Qualitative findings on how a community mobilisation intervention to prevent violence against women created change in Kampala, Uganda. Global Health Action 7: 25082. [CrossRef] [PubMed]

World Health Organization, and London School of Hygiene and Tropical Medicine. 2010. Preventing Intimate Partner and Sexual Violence against Women: Taking Action and Generating Evidence. Geneva: World Health Organization.

Pronyk, Paul M., James R. Hargreaves, Julia C. Kim, Linda A. Morison, Godfrey Phetla, Charlotte Watts, Joanna Busza, and John D. H. Porter. 2006. Effect of a structural intervention for the prevention of intimate-partner violence and HIV in rural South Africa: A cluster randomised trial. Lancet 368: 1973-83. [CrossRef]

Slegh, Henny, Gary Barker, Augustin Kimonyo, Prudence Ndolimana, and Matt Bannerman. 2013. 'I can do women's work': Reflections on engaging men as allies in women's economic empowerment in Rwanda. Gender E Development 21: 15-30. [CrossRef]

Starmann, Elizabeth, Martine Collumbien, Nambusi Kyegombe, Karen Devries, Lori Michau, Tina Musuya, Charlotte Watts, and Lori Heise. 2017. Exploring Couples' Processes of Change in the Context of SASA!, a Violence against Women and HIV Prevention Intervention in Uganda. Prevention Science 18: $233-44$. [CrossRef] [PubMed]

Verma, Ravi K., Julie Pulerwitz, Vaishali Mahendra, Sujata Khandekar, Gary Barker, P. Fulpagare, and S. K. Singh. 2006. Challenging and changing gender attitudes among young men in Mumbai, India. Reprod Health Matters 14: 135-43. [CrossRef]

Wadsworth, Martha E., and Howard J. Markman. 2012. Where's the Action? Understanding What Works and Why in Relationship Education. Behavior Therapy 43: 99-112. [CrossRef] 